\title{
2D Mesoporous Channels of PMO; a Platform for Cluster-Like Pt Synthesis and Catalytic Activity in Nitrophenol Reduction
}

\author{
Mohamed Esmat ${ }^{1,2,3} \mathbb{D}^{-}$, Hamed Mohtasham ${ }^{4}$, Yasser GadelHak ${ }^{3}{ }^{\oplus}$, Reza Tarbiat Mehrebani ${ }^{4}$, \\ Rafat Tahawy ${ }^{1}$, Sadegh Rostamnia ${ }^{4, *}$, , Naoki Fukata ${ }^{1,2}$, Samad Khaksar ${ }^{5}(\mathbb{C}$ \\ and Esmail Doustkhah 1,4,*(D) \\ 1 International Center for Materials Nanoarchitechtonics (MANA), National Institute for Materials \\ Science (NIMS), 1-1 Namiki, Tsukuba, Ibaraki 305-0044, Japan; mohamed.esmat@nims.go.jp (M.E.); \\ rafat_tahawy@yahoo.com (R.T.); FUKATA.Naoki@nims.go.jp (N.F.) \\ 2 Graduate School of Pure and Applied Sciences, University of Tsukuba, Tsukuba, Ibaraki 305-8573, Japan \\ 3 Materials Science and Nanotechnology Department, Faculty of Postgraduate Studies for Advanced \\ Sciences (PSAS), Beni-Suef University, 62511 Beni-Suef, Egypt; yasser191919@gmail.com \\ 4 Organic and Nano Group (ONG), Department of Chemistry, University of Maragheh, \\ 55181-83111 Maragheh, Iran; hamed.mohtasham@yahoo.com (H.M.); tarbiatreza@gmail.com (R.T.M.) \\ 5 Department of Chemistry, School of Science and Technology, The University of Georgia, Tbilisi 0171, \\ Georgia; samadkhaksar@yahoo.com \\ * Correspondence: srostamnia@gmail.com (S.R.); doustkhah.esmail@nims.go.jp (E.D.)
}

Received: 28 December 2019; Accepted: 21 January 2020; Published: 1 February 2020

\begin{abstract}
Thiourea-bridged organosiloxane is used to synthesize a periodic mesoporous organosilica (PMO). Since this PMO has an S-enriched surface, owing to thiourea functional groups, it exhibits strong coordination toward Pt ions, and it shows a high tunability in the Pt nanoparticles size. This hybrid mesoporous material is employed as a catalyst in the efficient reduction reaction of 4-nitrophenol to 4-aminophenol at room temperature in an aqueous media.
\end{abstract}

Keywords: periodic mesoporous organosilica; PMO; Pt nanoparticles; Reduction reaction; 4-nitrophenol

\section{Introduction}

Rapid industrialization and the release of pollutants are an overwhelming threat for green spaces and sustainable nature [1-6]. Specifically, the release of organic pollutants from industry (e.g., dyes and drug wastewater) and agriculture (e.g., fertilizers and pesticides) to groundwater and rivers are huge sources of pollution in the ecosystem. One of the most common organic classes of pollutants in industrial wastewaters is nitroaromatics. These are assumed to be toxic materials since they can damage kidney and liver in humans [7-9]. These compounds are being widely investigated to solve this issue. However, the challenges in this area have not been fully solved yet. 4-nitrophenol (4-NP) is a typical nitroaromatic compound that is considered to be toxic. However, many processes have been developed for 4-NP removal by reducing it to amino form or degradation with strong (photo)catalytic degradation methods. Catalytic reduction of 4-NP to p-aminophenol (p-AP) is an effective removal approach of 4-NP. Interestingly, 4-AP is considered to be a valuable intermediate product to manufacture many analgesics and antipyretic drugs (paracetamol, phenacetin) [10-15].

Very recently, noble metal nanoparticles (MNP), e.g., $\mathrm{Pt}, \mathrm{Pd}$, and $\mathrm{Au}$, have attracted wide attention due to their dominant (photo)catalytic activities in a variety of the reactions such as coupling, oxidation, reduction, and decomposition [16-26]. However, the high surface energy of MNPs results in easy 
agglomeration and consequent loss in catalytic activity which strongly discourages their application in the field of catalysis $[12,15,25,27]$. Therefore, the loading of MNPs on an appropriate nanostructure to harness the aggregation and stabilize the generated nanoparticles has been acknowledged as a favorable strategy to solve the current issue $[8,13,26,28]$. Besides, minimizing the size of MNPs toward a single atom is a newly emerging approach to maximize catalytic efficiency by direct involving the maximum number of atoms in the catalysis [29]. To achieve such accomplishments, the functional groups of the surface in support may play a crucial role in determining the fate of nanoparticles. Sulfur-based functional groups can be superior functional groups to accomplish this. Among MNPs, $\mathrm{Pt}$ with a relatively lower price and diverse catalytic activity have attracted a great attention and been extensively applied in different catalytic reactions $[16,17,20,25,30,31]$.

In the recent decade, periodic mesoporous organosilica (PMO) materials with an ordered porous structure and wide variety of organic moiety, tunable architecture, and high surface area have been widely employed in the heterogeneous and green design of the catalysts [19,32-37]. Some of them might be promising candidates to generate and support sub- $2 \mathrm{~nm}$ sized MNPs with uniform distribution, which is the key to attaining high catalytic performance [38-41]. We studied the tenability of organosiloxane precursors with TEOS in the rational synthesis of PMOs [41]. Very recently, we also synthesized 1,3-bis(3-(triethoxysilyl) propyl) thiourea (BTSPT) through a new approach and incorporated it to synthesize a new thiourea-bridged PMO (PMO-TU) with a perfect 2D hexagonal mesostructure (Scheme 1). This thiourea-bridged PMO was successfully incorporated for ultrasmall Pd nanoparticles with a high uniformity and stability which showed an excellent catalytic activity toward formic acid dehydrogenation and coupling reaction [19,40]. Here, we present the synthesis of ultra-small and uniform Pt nanoparticles, which is successfully deposited on the surface of the PMO-TU and employed in the catalytic reduction of 4-NP to 4-AP by Pt supported PMO-TU (Pt@PMO-TU).

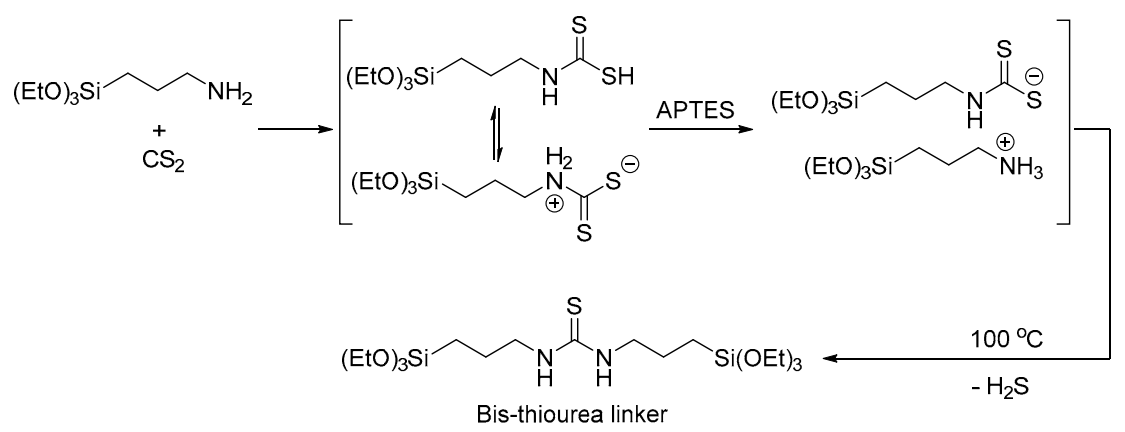

Scheme 1. Procedures for the synthesis of the bis-thiourea linker.

\section{Results and Discussion}

We synthesized PMO-TU in the presence of a triblock copolymer, P123 (poly(ethylene glycol)-block-poly(propylene glycol)-block-poly(ethylene glycol)), and employed it as unique support for the synthesis of sub-2 nm Pt nanoparticles. Then, we characterized these materials using different instruments. To check whether the functional groups are created and preserved during the synthesis process of PMO, we checked the FTIR spectra of BTSPT, PMO-TU and Pt@PMO-TU (Figure 1a). A broad band at $3265 \mathrm{~cm}^{-1}$ is attributable to N-H stretching of the thiourea group. Two characteristic peaks at 2974 and $2928 \mathrm{~cm}^{-1}$ correspond to the asymmetric and symmetric stretching modes of aliphatic $\mathrm{C}-\mathrm{H}$ bonds in propyl chain, respectively. A peak at $1553 \mathrm{~cm}^{-1}$ may refer to $\mathrm{C}=\mathrm{S}$ bond stretching of the thiourea. Another peak at $1167 \mathrm{~cm}^{-1}$ corresponds to the stretching mode of $\mathrm{C}-\mathrm{N}$ bond. Another two peaks at 1104 and $1080 \mathrm{~cm}^{-1}$ relate to the $\mathrm{Si}-\mathrm{O}-\mathrm{Si}$ linkage. Additionally, thermal gravimetric analysis (TGA) of Pt@PMO-TU confirms the existence of the organic thiourea (Figure 1b). The weight loss, starting from $200{ }^{\circ} \mathrm{C}$ to $500{ }^{\circ} \mathrm{C}$ can be related to the thiourea bridges of PMO-TU, which is approximately $\sim 12 \mathrm{wt} \%$. Based on the $\%$ of weight loss, the mol\% of PMO and the organic moiety (TU) can be estimated as $1.5 \mathrm{~mol} \%$ and $0.16 \mathrm{~mol} \%$, respectively. 
a)
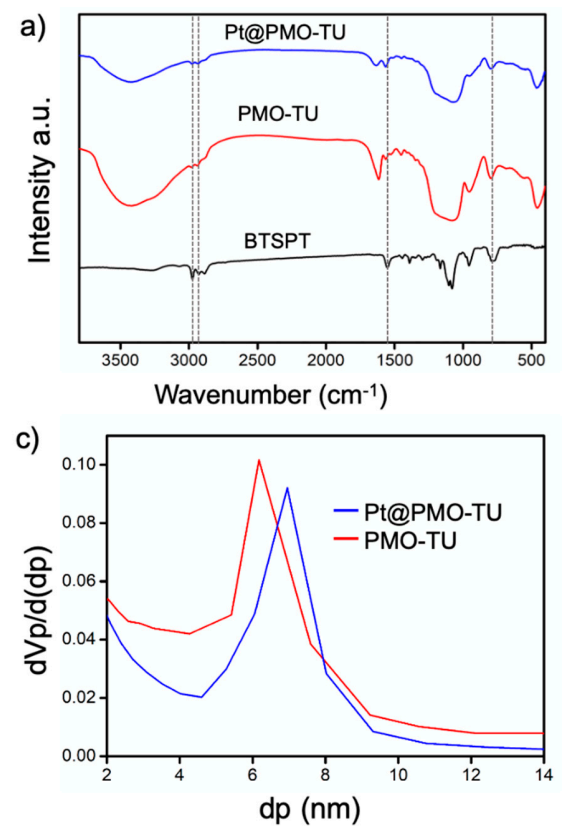
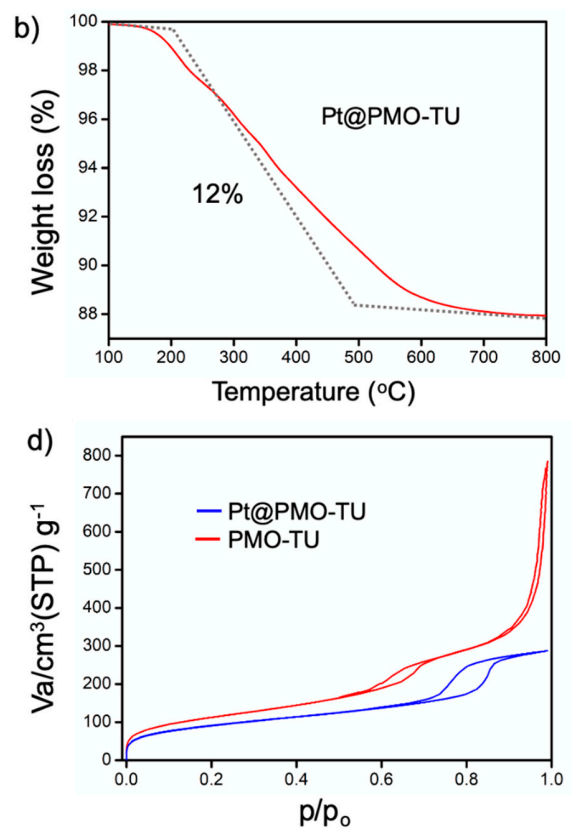

Figure 1. (a) FT-IR for 1,3-bis(3-(triethoxysilyl)propyl) thiourea (BTSPT), thiourea-bridged periodic mesoporous organosilica (PMO-TU) and Pt@PMO-TU, (b) thermal gravimetric analysis (TGA) of Pt@PMO-TU and (c,d), respectively, Nitrogen adsorption-desorption isotherms and corresponding pore-size distribution curves of both PMO-TU and Pt/PMO-TU.

The $\mathrm{N}_{2}$ adsorption-desorption isotherm of both PMO-TU and Pt/PMO-TU, as shown in Figure $1 \mathrm{c}, \mathrm{d}$, show a type IV behavior which is a representative of SBA-like mesoporous material [19,42]. The BET surface area for PMO-TU and Pt/PMO-TU was calculated to be 475 and $331.8 \mathrm{~m}^{2} \cdot \mathrm{g}^{-1}$, respectively. Pt loading over the PMO support has caused less than $30 \%$ reduction in the value of the exposed surface area which confirms that the structure has not experienced a significant loss in the mesoporosity [19]. The total pore volume was calculated to be $1.19 \mathrm{~cm}^{3} \cdot \mathrm{g}^{-1}$ for the PMO-TU support and decreased to $0.388 \mathrm{~cm}^{3} \cdot \mathrm{g}^{-1}$ after Pt loading owing to the volume occupied by Pt nanoparticles deposited inside the pores. The average pore diameter has not changed significantly and was estimated to be $6.18 \pm 0.61 \mathrm{~nm}$ and $6.9 \pm 0.7 \mathrm{~nm}$ for the PMO-TU and Pt/PMO-TU composite, respectively.

Figure 2a shows a scanning electron micrograph for the PMO-TU support which has the morphology of entangled rod-like structures with an average diameter of $200 \mathrm{~nm}$. The HRTEM micrograph (Figure $2 \mathrm{~b}$ ) reveals the ordered hexagonal symmetry of the PMO-TU substrate with a periodic honeycomb arrangement. Figure $2 \mathrm{c}$ shows the finely well-distributed $\mathrm{Pt}$ nanoparticles after deposition over the PMO-TU support. Figure $2 \mathrm{~d}$ shows the morphology of the Pt/PMO-TU nanocomposite after being used as a catalyst for the reduction of 4-NP. It can be observed that the PMO still preserves its morphology without significant changes after being used as a catalyst, indicating its structural stability. 

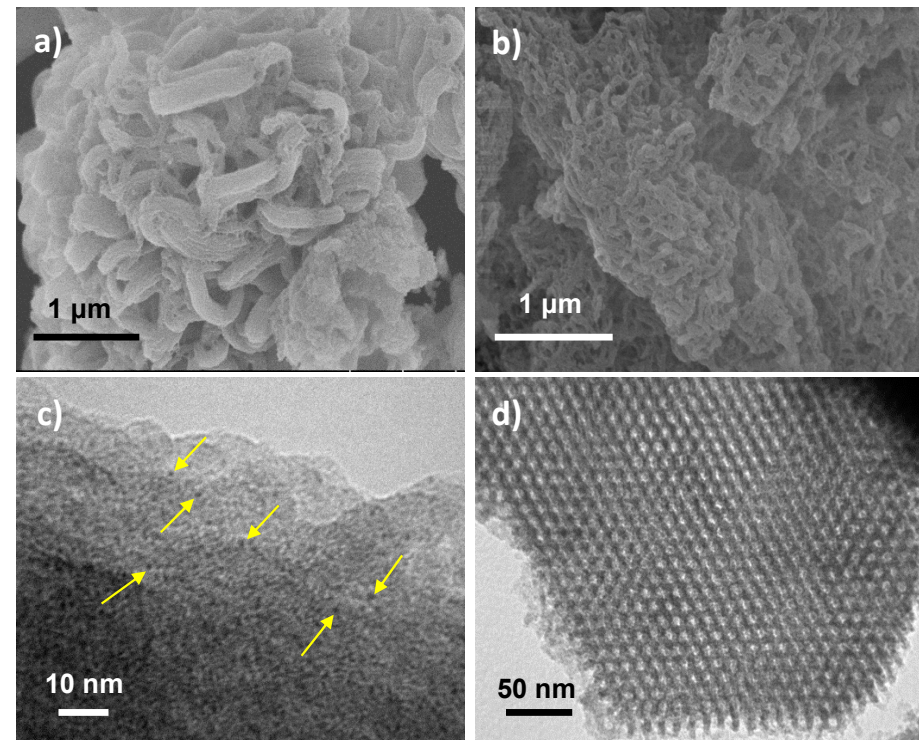

Figure 2. (a,b) SEM micrograph of thiourea-bridged periodic mesoporous organosilica (PMO-TU) support, (b) SEM micrograph of Pt/PMO-TU nanocomposite, (c) HRTEM micrograph of PMO-TU support (yellow arrows show the supported Pt nanoparticles), and (d) HRTEM micrograph of the $\mathrm{Pt} / \mathrm{PMO}-\mathrm{TU}$ nanocomposite.

The loading of fine Pt nanoparticles in the PMO-TU support can be visualized by observing the sample using a high-angle annular dark-field scanning transmission electron microscope (HAADF-STEM), indicated in Figure 3a,b. HAADF-STEM images further show a uniform ultra-small distribution of $\mathrm{Pt}$ nanoparticles with good dispersion throughout the structure. For better understanding, two points from the Pt/PMO-TU sample were selected under STEM observation and investigated by using the energy-dispersive X-ray spectroscopy (EDS), shown in Figure 3c,d. Both EDS spectra (001 and 002 positions) show the corresponding peaks of Pt which confirm the existence of Pt located in the PMO-TU substrate.
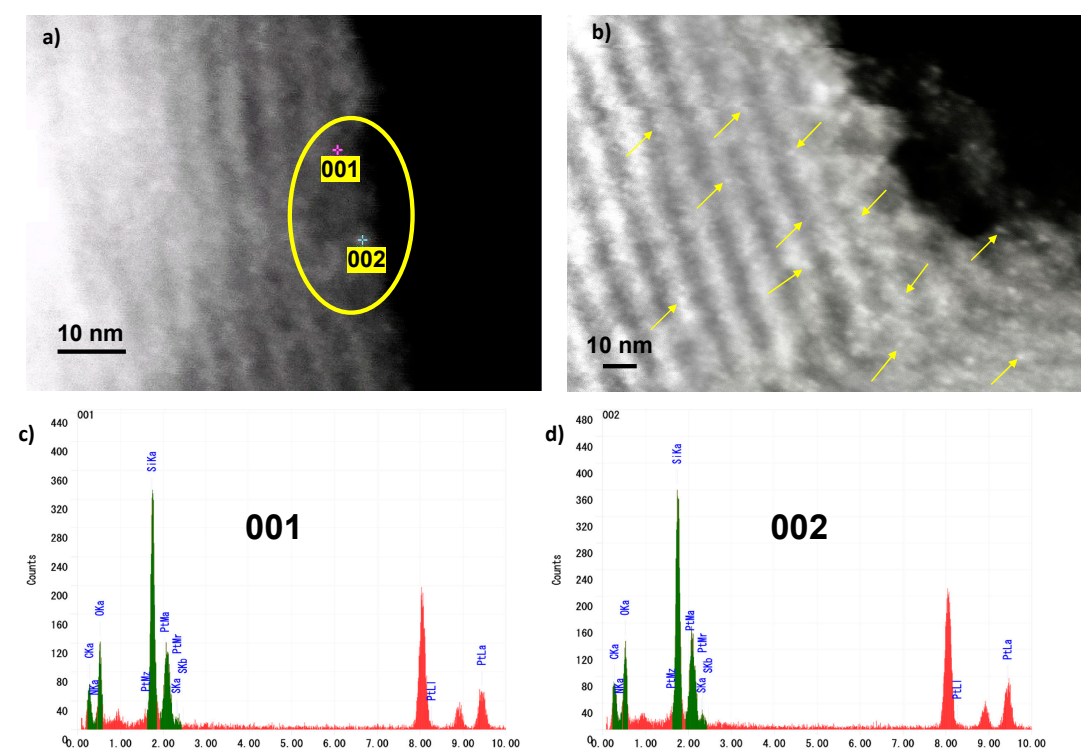

Figure 3. (a,b) high-angle annular dark-field scanning transmission electron microscope (HAADF-STEM) images of Pt@PMO-TU (yellow arrows show supported Pt nanoparticles), (c,d) energy-dispersive $\mathrm{X}$-ray spectroscopy (EDS) spectra of Pt/PMO-TU nanocomposite. 
The catalytic activity of the $\mathrm{Pt} / \mathrm{PMO}-\mathrm{TU}$ was tested for the reduction of 4-NP using $\mathrm{NaBH}_{4}$ as a reducing agent. As shown in Figure 4a, the PMO-TU substrate does not show any significant catalytic activity whereas the Pt/PMO-TU could reduce 4-NP totally in approximately $14 \mathrm{~min}$. Figure $4 \mathrm{~b}$ shows the time-dependent decrease in the absorption spectra of 4-NP leading to the formation of 4-AP (absorption peak at $293 \mathrm{~nm}$ ). This absorption peak confirms that the decrease in the concentration of 4-NP is due to actual catalytic conversion to produce 4-AP and not due to simple adsorption over the surface of the nanocomposite. Additionally, we studied the starting time and finishing time of the reaction by HPLC analysis (Figure S1) and we found that the results are consistent with UV-Vis data in Figure $4 b$.
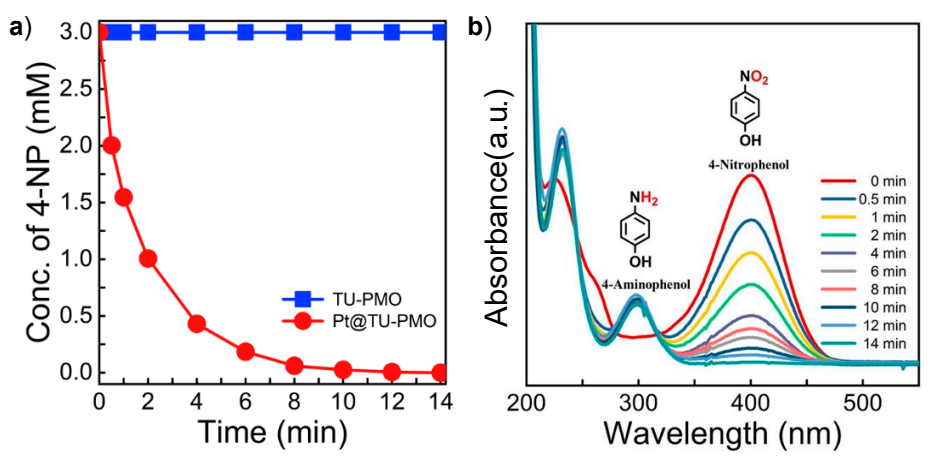

Figure 4. (a) Time-dependences of the absorbances at $400 \mathrm{~nm}$ for the reduction of 4-NP with $\mathrm{NaBH}_{4}$ in the presence of PMO-TU and Pt/PMOTU and (b) absorption spectra for the reduction of 4-nitrophenol, Conditions: $[4-\mathrm{PN}]=3 \mathrm{mM},\left[\mathrm{NaBH}_{4}\right]=125 \mathrm{mM}$, [Catalyst $]=10 \mathrm{mg}, \mathrm{T}=25^{\circ} \mathrm{C}$.

Figure 5a shows the effect of different reaction temperatures on the time-dependent decay of the 4 -NP. The reaction was conducted at 25,50 and $75^{\circ} \mathrm{C}$. As shown, increasing the reaction temperature leads to an increase in the reaction rate. The Arrhenius plot for such reaction is shown in Figure $5 \mathrm{~b}$ where the activation energy calculated from the plot was equal to $18.327 \mathrm{KJ} / \mathrm{mol}$. This value is the lowest reported so far (as far as the authors are aware) for the reduction of 4-NP over a Pt-based catalyst which indicated the catalytic superiority of the Pt/PMO-TU towards 4-NP reduction. The effect of changing the Pt/PMO-TU catalyst dose on the reaction rate was investigated and the results are shown in Figure 6a. It can be shown that increasing the catalyst dose to $20 \mathrm{mg}$ leads to the complete reduction of 4-NP in approximately four minutes. The relation between the catalyst dose and the first-order reaction constant is shown in Figure $6 \mathrm{~b}$ where a linear relation can be observed.
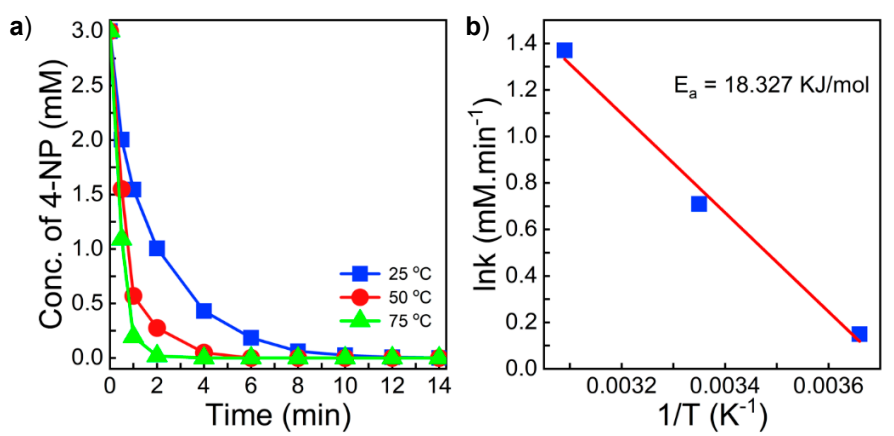

Figure 5. (a) Time-dependences of the absorbances at $400 \mathrm{~nm}$ for the reduction of 4-NP with $\mathrm{NaBH}_{4}$ in the presence Pt/PMO-TU and (b) Arrhenius plot (ln k versus 1/T) Conditions: [4-PN] $=3 \mathrm{mM}$, $\left[\mathrm{NaBH}_{4}\right]=125 \mathrm{mM}$, [Catalyst $]=10 \mathrm{mg}, \mathrm{T}=25,50,75^{\circ} \mathrm{C}$. 

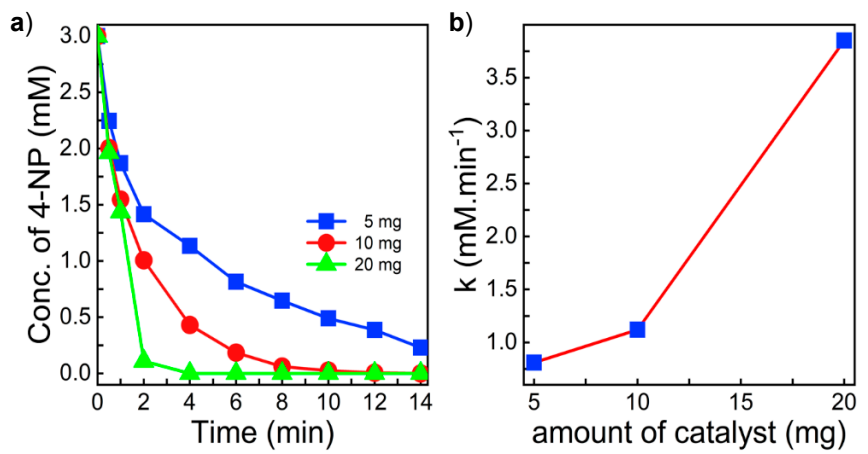

Figure 6. (a) Time-dependences of the absorbances at $400 \mathrm{~nm}$ for the reduction of $p$-NP with $\mathrm{NaBH}_{4}$ in the presence different dosage of $\mathrm{Pt} / \mathrm{PMO}-\mathrm{TU}$ and $(\mathbf{b})$ plot of rate constant $(\mathrm{k})$ versus catalyst dose. Conditions: $[4-\mathrm{PN}]=3 \mathrm{mM},\left[\mathrm{NaBH}_{4}\right]=125 \mathrm{mM}$, [Catalyst $]=5,10$ and $20 \mathrm{mg}, \mathrm{T}=25{ }^{\circ} \mathrm{C}$.

The initial concentration of $\mathrm{NaBH}_{4}$ was varied and the results are shown in Figure 5a. As shown, starting with an initial concentration of $250 \mathrm{mM}$ lead to the complete reduction of 4-NP in less than $1 \mathrm{~min}$. According to the authors' best knowledge, the shortest conversion time reported for the reduction of 4-NP was two minutes using Pt-Pd nanocubes supported on nitrogen doped hollow carbon nanospheres [7]. Figure $7 \mathrm{~b}$ indicates that increasing the $\mathrm{NaBH}_{4}$ concentration leads to a consequent increase in the value of the rate constant.
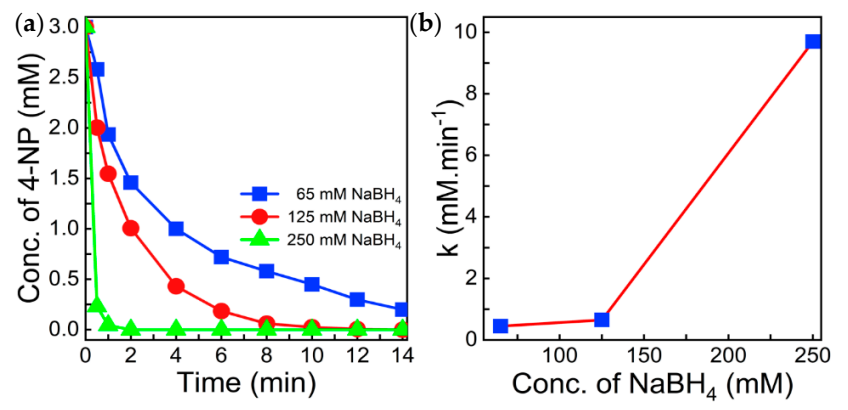

Figure 7. (a) Time-dependences of the absorbances at $400 \mathrm{~nm}$ for the reduction of $p$-NP with different initial concentrations of $\mathrm{NaBH}_{4}$ in the presence $\mathrm{Pt} / \mathrm{PMO}-\mathrm{TU}$ and $(\mathbf{b})$ plot of rate constant $(\mathrm{k})$ versus catalyst dose initial concentrations of $\mathrm{NaBH}_{4}$. Conditions: $[4-\mathrm{PN}]=3 \mathrm{mM},\left[\mathrm{NaBH}_{4}\right]=65,125$ and $250 \mathrm{mM}$, [Catalyst $]=10 \mathrm{mg}, \mathrm{T}=25^{\circ} \mathrm{C}$.

The stability of catalytic materials is a critical point. So, we evaluate the reusability of the Pt@PMO-TU catalyst by performing three cycles for 4-NP reduction. The results after each cycle showed high catalytic performance with efficient conversion (Figure 8), which points out the high stability and recyclability of our catalyst. Furthermore, we examined the reaction solution after three cycles by atomic adsorption spectroscopy (AAS) and the it shows that the leaching of Pt from PMO-TU is negligible. 


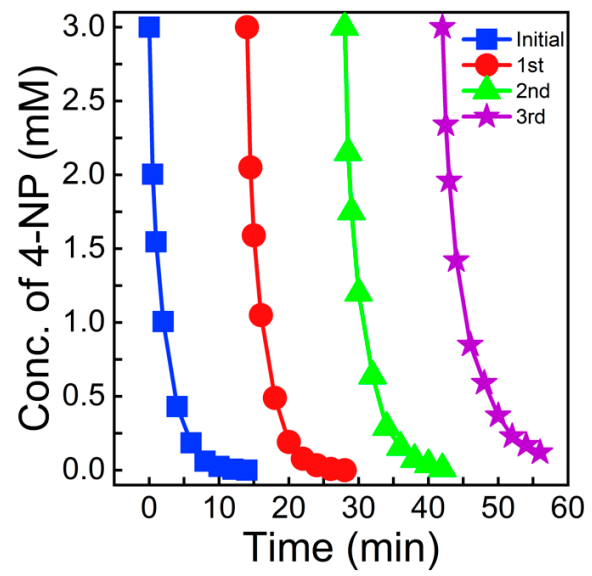

Figure 8. Reusability study of the Pt@PMU-TU catalyst.

To compare our results with the previous reports, we listed different types of catalysts in terms of time, conversion \% and reaction conditions, as summarized in Table 1. Interestingly, it can be remarked that the catalytic activity obtained by our material is outstanding when compared with the previously reported catalysts.

Table 1. Comparison of the activity of our catalyst with those previously reported.

\begin{tabular}{|c|c|c|c|c|}
\hline Catalyst & Conv. $(\%)$ & $t(\min )$ & Reaction Conditions & Ref. \\
\hline $\operatorname{AgPd~NCs/rGO~}$ & $95.6 \%$ & 3 & $\mathrm{NaBH}_{4}(5 \mathrm{mM}) ; p-\mathrm{NP}(0.7 \mathrm{mM}) ;$ catalyst $(0.05 \mathrm{mg}) ; \mathrm{rt}$ & [8] \\
\hline Pd-PBL & $98.3 \%$ & 32 & $\begin{array}{c}\mathrm{NaBH}_{4}\left(1 \times 10^{-4} \mathrm{mmol}\right) ; p-\mathrm{NP}\left(1 \times 10^{-3} \mathrm{mmol}\right) ; \text { catalyst } \\
(1 \mathrm{~mol} \%) ; \mathrm{rt}\end{array}$ & [43] \\
\hline $\mathrm{Au} / \mathrm{Fe}_{3} \mathrm{O}_{4}$ & $100 \%$ & 10 & $\mathrm{NaBH}_{4}(0.1 \mathrm{M}) ; p$-NP $(10 \mathrm{mM}) ;$ catalyst $(2 \mathrm{mg}) ; \mathrm{rt}$ & [44] \\
\hline $\mathrm{Au} / \mathrm{CNTs}$ membrane & $100 \%$ & 15 & $\mathrm{NaBH}_{4}(50 \mathrm{mM}) ; p-\mathrm{NP}(0.2 \mathrm{mM}) ;$ catalyst $(0.25 \mathrm{mM}) ; \mathrm{rt}$ & [28] \\
\hline Ag-OMS-C & $96 \%$ & 2.5 & $\mathrm{NaBH}_{4}(0.5 \mathrm{M}) ; p-\mathrm{NP}(0.1 \mathrm{mM}) ;$ catalyst $(10 \mathrm{mg}) ; \mathrm{rt}$ & [15] \\
\hline ZVI NCs & $100 \%$ & 1 & $\mathrm{NaBH}_{4}(3.2 \mathrm{mM}) ; p$-NP $(0.14 \mathrm{mM}) ;$ catalyst $(0.44 \mathrm{mM}) ; \mathrm{rt}$ & [45] \\
\hline PtPd@N-HCS & $100 \%$ & 2 & $\mathrm{NaBH}_{4}(0.1 \mathrm{M}) ; p-\mathrm{NP}(0.25 \mathrm{mM}) ;$ catalyst $(2 \mathrm{mg}) ; \mathrm{rt}$ & [7] \\
\hline Pt/PMO-TU & $100 \%$ & $<1$ & $\mathrm{NaBH}_{4}(250 \mathrm{mM}) ; p$-NP $(3 \mathrm{mM}) ;$ catalyst $(10 \mathrm{mg}) ; \mathrm{rt}$ & This work \\
\hline
\end{tabular}

ZVI: zero-valent iron; NCs: Nanoclusters; rGO: reduced graphene oxide; PBL: Phenylene-Bridged Bis(thione) Ligands; CNTs: carbon nanotubes; OMS-C: ordered mesoporous silica cubic; N-HCS: nanocube-hollow carbon nanosphere; rt: room temperature.

Revisiting the mechanism of 4-NP reduction on noble metal surface through $\mathrm{NaBH}_{4}$ (as reductant) by Chen and Li [46], 4-NP first deprotonates to 4-aminophenolate, then, approaches to the surface of metal (here $\mathrm{Pt}$ ) and accepts the electron and subsequently converts to the reduced form. The donated electron from metal is supplied by $\mathrm{NaBH}_{4}$. A plausible schematic for the reduction of 4-NP to 4-AP is presented in Scheme 2.

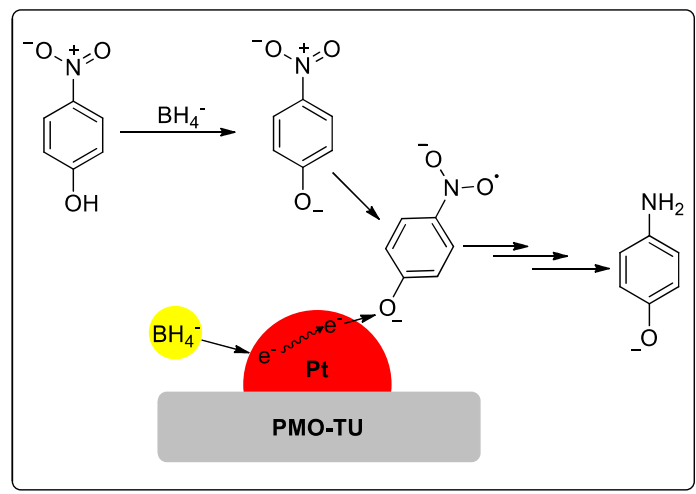

Scheme 2. The mechanism of 4-nitrophenol reduction (the ratio of Pt: 4-Nitrophenol: $\mathrm{NaBH}_{4}$ is 1:0.024:1.54 $\times 10^{-4}$, respectively). 


\section{Materials and Methods}

\subsection{Synthesis of Pt@PMO-TU}

PMO-TU was synthesized according to literature [19]. $\mathrm{PtCl}_{4}$ was first dissolved in a distilled water and then added to the dispersion of PMO-TU in ethanol while stirring. The dispersion was stirred for $1 \mathrm{~h}$ at room temperature and then, the solid was collected by centrifugation, washed with ethanol, and dried at $60{ }^{\circ} \mathrm{C}$ in an oven. The obtained solid in this step was redispersed in methanol and a methanolic solution of $\mathrm{NaBH}_{4} / \mathrm{MeOH}$ was added dropwise to the dispersion in stirring mode within $30 \mathrm{~min}$ at room temperature. Finally, the final product as a solid was centrifuged, washed, and dried at $60{ }^{\circ} \mathrm{C}$ and named Pt@PMO-TU. According to ICP-AES analysis, the wt\% of Pt was 1.5.

\subsection{Characterization}

FTIR spectra were collected using a Shimadzu IR-460 spectrometer. The morphology was observed with a HITACHI SU- 8230 microscope, operating at $10.0 \mathrm{kV}$. HRTEM images and EDX elemental maps were taken with a JEOL JEM-2100F microscope, operated at $200 \mathrm{kV}$. $\mathrm{N}_{2}$ adsorption-desorption isotherms were analyzed using a Quantachrome Autosorb at $77 \mathrm{~K}$. The Pt loading amount was recorded by inductively coupled plasma atomic emission spectroscopy (ICP-AES) on a Perkin Elmer 2100DV. Thermogravimetric curves were performed using a Hitachi TG/DTA6200. UV-vis spectra were obtained with a UV-1800 biotech. HPLC chromatograph was determined using Shimadzu LC-20AD.

\subsection{Catalytic Test}

Pt@PMO-TU (10 mg) was dispersed in an aqueous solution of 4-NP (3 mM, $40 \mathrm{~mL}$ ) and sonicated for $5 \mathrm{~min}$. Then, $\mathrm{NaBH}_{4}(5 \mathrm{mmol}, 190 \mathrm{mg}$ ) was added dropwise to the solution and stirred until the completing the reaction. During the reaction, sampling from reaction dispersion was performed by a syringe equipped with a syringe filter (for filtering the catalyst from the reaction media) and analyzed by UV-Vis spectrometer to monitor the reaction progress.

\section{Conclusions}

The synthesis of $\mathrm{Pt}$ nanoparticles with ultrasmall and uniform size in 2D mesochannels of thiourea-bridged periodic organosilica was confirmed by STEM technique. The catalytic activity of this PMO with Pt nanoparticles showed a high catalytic activity in the reduction of 4-nitrophenol. According to our study, the activation energy for this reaction in the presence of this catalyst was found to be $18.3 \mathrm{~kJ}$. mol${ }^{-1}$. All effective parameters on the catalytic activity of Pt@PMO-TU were studied and it was found that the catalyst is applicable at room temperature in aqueous media.

Supplementary Materials: The following are available online at http://www.mdpi.com/2073-4344/10/2/167/s1, Figure S1: HPLC chromatograph of 4-nitophenol (4-NP) and 4-aminophenol (4-AP).

Author Contributions: Conceptualization, E.D.; methodology, M.E. and H.M.; software, M.E. and H.M.; validation, M.E., Y.G. and E.D.; formal analysis, M.E. and H.M.; investigation, H.M., R.T.M. and R.T.; data curation, S.R., R.T.M. and S.K.; writing — original draft preparation, M.E. and Y.G; writing-review and editing, E.D.; supervision, S.R., N.F., S.K. and E.D.; project administration, S.R. and E.D. All authors have read and agreed to the published version of the manuscript.

Funding: This research received no external funding.

Conflicts of Interest: The authors declare no conflict of interest. 


\section{References}

1. El-Hosainy, H.; El-Sheikh, S.; Ismail, A.; Hakki, A.; Dillert, R.; Killa, H.; Ibrahim, I.; Bahnemann, D. Highly selective photocatalytic reduction of o-dinitrobenzene to o-phenylenediamine over non-metal-doped $\mathrm{TiO}_{2}$ under simulated solar light irradiation. Catalysts 2018, 8, 641. [CrossRef]

2. Esmat, M.; Farghali, A.A.; El-Dek, S.I.; Khedr, M.H.; Yamauchi, Y.; Bando, Y.; Fukata, N.; Ide, Y. Conversion of a 2D lepidocrocite-type layered titanate into its 1D nanowire form with enhancement of cation exchange and photocatalytic performance. Inorg. Chem. 2019, 58, 7989-7996. [CrossRef] [PubMed]

3. Doustkhah, E.; Lin, J.; Rostamnia, S.; Len, C.; Luque, R.; Luo, X.; Bando, Y.; Wu, K.C.-W.; Kim, J.; Yamauchi, Y.; et al. Development of sulfonic-acid-functionalized mesoporous materials: synthesis and catalytic applications. Chem. A Eur. J. 2019, 25, 1614-1635. [CrossRef] [PubMed]

4. Kobya, M.; Soltani, R.D.C.; Omwene, P.I.; Khataee, A. A review on decontamination of arsenic-contained water by electrocoagulation: Reactor configurations and operating cost along with removal mechanisms. Environ. Technol. Innov. 2020, 17, 100519. [CrossRef]

5. Doustkhah, E.; Ide, Y. Bursting exfoliation of a microporous layered silicate to three-dimensionally meso-microporous nanosheets for improved molecular recognition. ACS Appl. Nano Mater. 2019, 2, 7513-7520. [CrossRef]

6. Doustkhah, E.; Hasani, M.; Ide, Y.; Assadi, M.H.N. Pd nanoalloys for $\mathrm{H}_{2}$ generation from formic acid. ACS Appl. Nano Mater. 2019. [CrossRef]

7. Zhang, C.; Zhang, R.; He, S.; Li, L.; Wang, X.; Liu, M.; Chen, W. 4-nitrophenol reduction by a single platinum palladium nanocube caged within a nitrogen-doped hollow carbon nanosphere. ChemCatChem 2017, 9, 980-986. [CrossRef]

8. Zhu, X.Y.; Lv, Z.S.; Feng, J.J.; Yuan, P.X.; Zhang, L.; Chen, J.R.; Wang, A.J. Controlled fabrication of well-dispersed AgPd nanoclusters supported on reduced graphene oxide with highly enhanced catalytic properties towards 4-nitrophenol reduction. J. Colloid Interface Sci. 2018, 516, 355-363. [CrossRef]

9. Wang, Y.; Li, Q.; Zhang, P.; O'Connor, D.; Varma, R.S.; Yu, M.; Hou, D. One-pot green synthesis of bimetallic hollow palladium-platinum nanotubes for enhanced catalytic reduction of $p$-nitrophenol. J. Colloid Interface Sci. 2019, 539, 161-167. [CrossRef]

10. El-Sheikh, S.M.; Ismail, A.A.; Al-Sharab, J.F. Catalytic reduction of p-nitrophenol over precious metals/highly ordered mesoporous silica. New J. Chem. 2013, 37, 2399-2407. [CrossRef]

11. Yang, Y.; Zhang, Y.; Sun, C.J.; Li, X.; Zhang, W.; Ma, X.; Ren, Y.; Zhang, X. Heterobimetallic metal-organic framework as a precursor to prepare a nickel/nanoporous carbon composite catalyst for 4-nitrophenol reduction. Chem CatChem 2014, 6, 3084-3090. [CrossRef]

12. Qiao, X.Q.; Zhang, Z.W.; Tian, F.Y.; Hou, D.F.; Tian, Z.F.; Li, D.S.; Zhang, Q. Enhanced catalytic reduction of p-nitrophenol on ultrathin $\mathrm{MoS}_{2}$ nanosheets decorated with noble metal nanoparticles. Cryst. Growth Des. 2017, 17, 3538-3547. [CrossRef]

13. Al-Kahtani, A.A.; Almuqati, T.; Alhokbany, N.; Ahamad, T.; Naushad, M.; Alshehri, S.M. A clean approach for the reduction of hazardous 4-nitrophenol using gold nanoparticles decorated multiwalled carbon nanotubes. J. Clean. Prod. 2018, 191, 429-435. [CrossRef]

14. Bai, Y.; Wang, Q.; Du, C.; Bu, T.; Liu, Y.; Sun, X.; Luo, W.; Li, R.; Zhao, Y.; Zheng, X.; et al. Three-dimensional $\mathrm{Cu} / \mathrm{C}$ porous composite: Facile fabrication and efficient catalytic reduction of 4-nitrophenol. J. Colloid Interface Sci. 2019, 553, 768-777. [CrossRef] [PubMed]

15. Fan, H.T.; Liu, X.G.; Xing, X.J.; Li, B.; Wang, K.; Chen, S.T.; Wu, Z.; Qiu, D.F. Ordered mesoporous silica cubic particles decorated with silver nanoparticles: A highly active and recyclable heterogeneous catalyst for the reduction of 4-nitrophenol. Dalton Trans. 2019, 48, 2692-2700. [CrossRef]

16. Guo, S.; Sun, S. FePt nanoparticles assembled on graphene as enhanced catalyst for oxygen reduction reaction. J. Am. Chem. Soc. 2012, 134, 2492-2495. [CrossRef]

17. Zhang, Y.; Zhou, Y.; Huang, L.; Zhou, S.; Sheng, X.; Wang, Q.; Zhang, C. Structure and catalytic properties of the Zn-modified ZSM-5 supported platinum catalyst for propane dehydrogenation. Chem. Eng. J. 2015, 270, 352-361. [CrossRef]

18. Jiang, X.; Han, B.; Zhou, C.; Xia, K.; Gao, Q.; Wu, J. Cu nanoparticles supported on oxygen-rich boron nitride for the reduction of 4-nitrophenol. ACS Appl. Nano Mater. 2018, 1, 6692-6700. [CrossRef] 
19. Doustkhah, E.; Rostamnia, S.; Imura, M.; Ide, Y.; Mohammadi, S.; Hyland, C.J.T.; You, J.; Tsunoji, N.; Zeynizadeh, B.; Yamauchi, Y. Thiourea bridged periodic mesoporous organosilica with ultra-small Pd nanoparticles for coupling reactions. RSC Adv. 2017, 7, 56306-56310. [CrossRef]

20. Gao, Y.; Zhang, Y.; Zhou, Y.; Zhang, C.; Zhang, H.; Zhao, S.; Fang, J.; Huang, M.; Sheng, X. Synthesis of ordered mesoporous $\mathrm{La}_{2} \mathrm{O}_{3}-\mathrm{ZrO}_{2}$ composites with encapsulated Pt NPs and the effect of La-dopping on catalytic activity. J. Colloid Interface Sci. 2017, 503, 178-185. [CrossRef]

21. Karimi-Maleh, H.; Shojaei, A.F.; Karimi, F.; Tabatabaeia, K.; Shakeri, S. Au nanoparticle loaded with 6-thioguanine anticancer drug as a new strategy for drug delivery. J. Nanostruct. 2018, 8, 417-424.

22. Yola, M.L.; Atar, N.; Eren, T.; Karimi-Maleh, H.; Wang, S. Sensitive and selective determination of aqueous triclosan based on gold nanoparticles on polyoxometalate/reduced graphene oxide nanohybrid. RSC Adv. 2015, 5, 65953-65962. [CrossRef]

23. Baghayeri, M.; Namadchian, M.; Karimi-Maleh, H.; Beitollahi, H. Determination of nifedipine using nanostructured electrochemical sensor based on simple synthesis of Ag nanoparticles at the surface of glassy carbon electrode: Application to the analysis of some real samples. J. Electroanal. Chem. 2013, 697, 53-59. [CrossRef]

24. Karimi-Maleh, H.; Sheikhshoaie, I.; Samadzadeh, A. Simultaneous electrochemical determination of levodopa and piroxicam using a glassy carbon electrode modified with a ZnO-Pd/CNT nanocomposite. RSC Adv. 2018, 8, 26707-26712. [CrossRef]

25. Wu, S.; Liu, J.; Ye, Y.; Tian, Z.; Li, P.; Cai, Y.; Lin, Y.; Liang, C. In-situ reactive loading of platinum onto tin oxide nanocrystals with superior catalytic performance for hydrogenation of 4-nitrophenol. Appl. Surf. Sci. 2019, 471, 469-474. [CrossRef]

26. Rath, P.C.; Saikia, D.; Mishra, M.; Kao, H.M. Exceptional catalytic performance of ultrafine $\mathrm{Cu}_{2} \mathrm{O}$ nanoparticles confined in cubic mesoporous carbon for 4-nitrophenol reduction. Appl. Surf. Sci. 2018, 427, 1217-1226. [CrossRef]

27. Esmat, M.; Farghali, A.A.; Khedr, M.H.; El-Sherbiny, I.M. Alginate-based nanocomposites for efficient removal of heavy metal ions. Int. J. Biol. Macromol. 2017, 102, 272-283. [CrossRef]

28. Wang, H.; Dong, Z.; Na, C. Hierarchical carbon nanotube membrane-supported gold nanoparticles for rapid catalytic reduction of $p$-nitrophenol. ACS Sustain. Chem. Eng. 2013, 1, 746-752. [CrossRef]

29. Lang, R.; Xi, W.; Liu, J.C.; Cui, Y.T.; Li, T.; Lee, A.F.; Chen, F.; Chen, Y.; Li, L.; Li, L.; et al. Non defect-stabilized thermally stable single-atom catalyst. Nat. Commun. 2019, 10, 234. [CrossRef]

30. Zhang, C.; Zhou, Y.; Zhang, Y.; Zhao, S.; Fang, J.; Sheng, X.; Zhang, H. Self-Assembly hierarchical silica nanotubes with vertically aligned silica nanorods and embedded platinum nanoparticles. ACS Sustain. Chem. Eng. 2017, 5, 1578-1585. [CrossRef]

31. Wang, Z.; Zhang, H.; Chen, L.; Miao, S.; Wu, S.; Hao, X.; Zhang, W.; Jia, M. Interfacial synergy of PtPd nanoparticles dispersed on amine-modified ZrSBA-15 in catalytic dehydrogenation of ammonia borane and reduction of $p$-nitrophenol. J. Phys. Chem. C 2018, 122, 12975-12983. [CrossRef]

32. Liu, C.; Tan, R.; Yu, N.; Yin, D. Pt-Pd bi-metal nanoparticles captured and stabilized by imine groups in a periodic mesoporous organosilica of SBA-15 for hydrogenation of nitrobenzene. Microporous Mesoporous Mater. 2010, 131, 162-169. [CrossRef]

33. Karimi, B.; Kabiri Esfahani, F. Unexpected golden Ullmann reaction catalyzed by Au nanoparticles supported on periodic mesoporous organosilica (PMO). Chem. Commun. 2011, 47, 10452-10454. [CrossRef] [PubMed]

34. Karimi, B.; Esfahani, F.K. Gold nanoparticles supported on the periodic mesoporous organosilicas as efficient and reusable catalyst for room temperature aerobic oxidation of alcohols. Adv. Synth. Catal. 2012, 354, 1319-1326. [CrossRef]

35. Karimi, B.; Gholinejad, M.; Khorasani, M. Highly efficient three-component coupling reaction catalyzed by gold nanoparticles supported on periodic mesoporous organosilica with ionic liquid framework. Chem. Commun. 2012, 48, 8961-8963. [CrossRef]

36. Doustkhah, E.; Mohtasham, H.; Hasani, M.; Ide, Y.; Rostamnia, S.; Tsunoji, N.; Hussein, M. Merging periodic mesoporous organosilica (PMO) with mesoporous aluminosilica (Al/Si-PMO): A catalyst for green oxidation. Mol. Catal. 2019. [CrossRef]

37. Huang, X.; Zhang, M.; Wang, M.; Li, W.; Wang, C.; Hou, X.; Luan, S.; Wang, Q. Gold/periodic mesoporous organosilicas with controllable mesostructure by using compressed $\mathrm{CO}_{2}$. Langmuir 2018, 34, 3642-3653. [CrossRef] 
38. Karimi, B.; Naderi, Z.; Khorasani, M.; Mirzaei, H.M.; Vali, H. Ultrasmall platinum nanoparticles supported inside the nanospaces of periodic mesoporous organosilica with an imidazolium network: an efficient catalyst for the aerobic oxidation of unactivated alcohols in water. ChemCatChem 2016, 8, 906-910. [CrossRef]

39. Dai, J.; Zou, H.; Wang, R.; Wang, Y.; Shi, Z.; Qiu, S. Yolk-shell Fe $\mathrm{O}_{4} @ S_{2} \mathrm{O}_{2} @ P M O:$ Amphiphilic magnetic nanocomposites as an adsorbent and a catalyst with high efficiency and recyclability. Green Chem. 2017, 19, 1336-1344. [CrossRef]

40. Doustkhah, E.; Rostamnia, S.; Zeynizadeh, B.; Kim, J.; Yamauchi, Y.; Ide, Y. Efficient $\mathrm{H}_{2}$ generation using thiourea-based periodic mesoporous organosilica with Pd nanoparticles. Chem. Lett. 2018, 47, 1243-1245. [CrossRef]

41. Doustkhah, E.; Mohtasham, H.; Farajzadeh, M.; Rostamnia, S.; Wang, Y.; Arandiyan, H.; Assadi, M.H.N. Organosiloxane tunability in mesoporous organosilica and punctuated Pd nanoparticles growth; theory and experiment. Microporous Mesoporous Mater. 2019, 293, 109832. [CrossRef]

42. Zaki, A.H.; El-Shafey, A.; Moatmed, S.M.; Abdelhay, R.A.; Rashdan, E.F.; Saleh, R.M.; Abd-El Fatah, M.; Tawfik, M.M.; Esmat, M.; El-dek, S.I. Morphology transformation from titanate nanotubes to $\mathrm{TiO}_{2}$ microspheres. Mater. Sci. Semicond. Process. 2018, 75, 10-17. [CrossRef]

43. Jia, W.-G.; Gao, L.-L.; Wang, Z.-B.; Sun, L.-Y.; Han, Y.-F. Synthesis, characterization, and catalytic activities of palladium complexes with phenylene-bridged bis(thione) ligands. Organometallics 2019, 38, 1946-1954. [CrossRef]

44. Lin, F.; Doong, R. Bifunctional $\mathrm{Au}-\mathrm{Fe}_{3} \mathrm{O}_{4}$ heterostructures for magnetically recyclable catalysis of nitrophenol reduction. J. Phys. Chem. C 2011, 115, 6591-6598. [CrossRef]

45. Shi, D.; Zhu, G.; Zhang, X.; Zhang, X.; Li, X.; Fan, J. Ultra-small and recyclable zero-valent iron nanoclusters for rapid and highly efficient catalytic reduction of: $p$-nitrophenol in water. Nanoscale 2019, 11, 1000-1010. [CrossRef]

46. Li, M.; Chen, G. Revisiting catalytic model reaction $p$-nitrophenol/ $\mathrm{NaBH}_{4}$ using metallic nanoparticles coated on polymeric spheres. Nanoscale 2013, 5, 11919-11927. [CrossRef]

(C) 2020 by the authors. Licensee MDPI, Basel, Switzerland. This article is an open access article distributed under the terms and conditions of the Creative Commons Attribution (CC BY) license (http://creativecommons.org/licenses/by/4.0/). 